\title{
GAY IDENTITY AND RISKY SEXUAL BEHAVIOR RELATED TO THE AIDS THREAT
}

\author{
K. Michael Joseph, MSW; S. Maurice Adib, MD, MPH; \\ Jill G. Joseph, PhD; Margalit Tal, MA
}

\begin{abstract}
This paper explores the relationship between risky sexual behavior and issues of gay identity in homosexual men. We identify three main conceptual categories important to gay identity: sexual identity, gay social interaction, and identity development milestones. Each of these categories are analyzed as to their predictive effect on risky sexual behavior related to the threat of HIV, at six-month and eighteen-month intervals. The results suggest that successful integration into a gay network plays a role in reducing risky sexual behavior among homosexual men, regardless of the chronological timing of personal events marking a gay man's "coming out" history.
\end{abstract}

\section{INTRODUCTION}

Homosexual and sexual men in the United States (US) remain at increased risk for Human Immunodeficiency Virus (HIV) infection and Acquired Immunodeficiency Syndrome (AIDS). In response to the HIV epidemic, dramatic sexual behavior change has reported in studies of homosexual men in different areas of the United States. ${ }^{2}$ A substantial number of men, however, have either not changed their behavior or failed to maintain previous change. ${ }^{3}$ As Joseph and Becker noted, "even the simplest transmission models suggest that a small group of particularly active individuals can prolong and/or extend this epidemic". ${ }^{4}$ This fact is important in determining the epidemic's future. Identifying factors associated with the inability of some gay men to reduce risky sexual

Jill G. Joseph is Associate Professor of Epidemiology; K. Michael Joseph and S. Maurice Adib are Research Assistants; Margalit Tal is a Research Associate; all at the School of Public Health, University of Michigan, Ann Arbor, Michigan 48109.

This study was funded by (1) the National Institute of Mental Health (2R01 MH39346 and $1 \mathrm{R} 01 \mathrm{MH} 00507$ ) and (2) the University of Michigan. The authors appreciate the contribution of biomedical data by the Chicago Multicenter AIDS Cohort Study (AI-32535 from the National Institute of Allergy and Infectious Diseases). We are grateful for the continuing assistance of Howard Brown Memorial Clinic in data collection.

Requests for reprints should be addressed to: Jill G. Joseph, PhD, The University of Michigan, School of Public Health, Department of Epidemiology, 109 Observatory, Ann Arbor, MI 48109 .

C 1991 Human Sciences Press, Inc. 
behavior can be crucial in enhancing the effectiveness of current preventive interventions.

The frequency and types of sexual behavior have been among the variables associated with the expression of gay identity in homosexual men. ${ }^{5}$ Still, one must keep in mind that sexual activity is not the sole determinant of gay identity. As Cass notes, "there is no such thing as a single homosexual identity. Rather, its nature may vary from person to person, from situation to situation and from period to period." In this paper we examine the effect of a wide range of gay identity variables such as attitudes, beliefs, social support and life events, all associated with "gay identity" by other researchers, on willingness to reduce risky sexual behavior among gay men. ${ }^{7-11}$

\section{METHODS}

Data were collected from the Chicago component of the Multicenter AIDS Cohort Study (MACS), conducted among self-declared gay men not diagnosed with AIDS, starting in June 1984. The study design and the composition of the cohort have been described in more detail elsewhere. ${ }^{12}$ Participants in the MACS have been invited to enroll concomitantly in the National Institute of Mental Health (NIMH) sponsored "Coping and Change Study" (CCS), investigation behavioral and psychosocial issues related to the threat of AIDS. ${ }^{13,14}$ Men agreeing to participate in the CCS are given a questionnaire at the time of their MACS bi-annual visit, to be completed at home two weeks after this visit, and mailed back.

The analysis included men who completed the CCS questionnaire at the first MACS visit (V1), the second (V2) six months later, and the fourth (V4) one and a half years later. The cohort at Vl was composed of 674 men, the majority of whom were white (92 percent). At the time of recruitment (1984), these men had an average age of 35 years, an average income of $\$ 24,500 /$ year and an average educational attainment of 16.3 years. Men who had been paid for $\operatorname{sex}(n=16)$ were excluded from this analysis. Independent variables measured at baseline (V1) were evaluated as determinants of behavioral outcomes at short (V2) and long-term (V4) intervals.

\section{Independent Variables}

Independent variables believed to be associated with gay identity fell into three conceptual categories: a personal dimension ("sexual identity"), a historical dimension ("identity development milestones"), and a social dimension ("gay social identity").

Sexual identity refers to one's sexual orientation, as well as one's self- 
concept as a sexual being, and one's attitudes towards sexual activity. ${ }^{6}$ As such, it is part but not all of gay identity. Included in this category were the following variables: sexual risk behavior at $\mathrm{Vl}$, importance attached to sexual activity ("Sexual activity means a lot to me"), ability to control sexual impulses ("I find it difficult to control my sexual impulses"), and five needs met by sex: sex to express love, sex to express power, sex to have fun, sex to reduce tension, and sex as a response to a partner's desire. An index of personal attitude to gay indentity, representing one's commitment to one's sexual identity, was also included in this category. (Details of construction available upon request.)

Identity developmental milestone events included: acceptance of one's gay identity, hereafter referred to as "coming out" to oneself ("When did you first consider yourself gay?"), "coming out" to non-gays ("When did you first tell a non-gay person that you are gay?") and first gay relationship that lasted at least six months.

Gay social identity included four variables. The first one, social participation with other gay men ("How much of your leisure time is spent socializing with gay men"), is a measure of development of interpersonal social skills. The three other variables are constructed indices: perception of hostility in heterosexuals' attitudes towards gay men, support in "coming out" from significant others (family members and non-gay friends), and support in "coming out" at work.

\section{Dependent Variable}

An index was created to describe engaging in risky sexual behavior. This Behavioral Risk Index (RBI) was based on reported frequency and practice of receptive anal sex and types of sexual partners, during the month preceding the completion of the questionnaire (see Table 1 for a summary of the $B R I)$. A missing response on any one of the questionnaire items used in constructing the BRI was arbitrarily assigned the highest risk level available, to ensure that outcome of interest in this analysis would not be accidentally underestimated (such situations occurred in less than 3 percent of cases).

The incidence of HIV seroconversion was compared among levels of BRI. In the celibate group, no seroconversions were reported, while in the low risk group, a seroconversion rate of 1.75 per 100 person-years was found. This rate was 10.9 in the modified high risk group and 14 in the highest risk group, suggesting that the BRI was indeed a valid summary of risk in sexual practices. ${ }^{14}$

\section{Research Questions}

Figure 1 presents a hypothetical predictive model of risk sexual behavior. In relation to this model, our study addresses two main questions:

1. What identity variables are significant determinants of risk sexual behavior? 


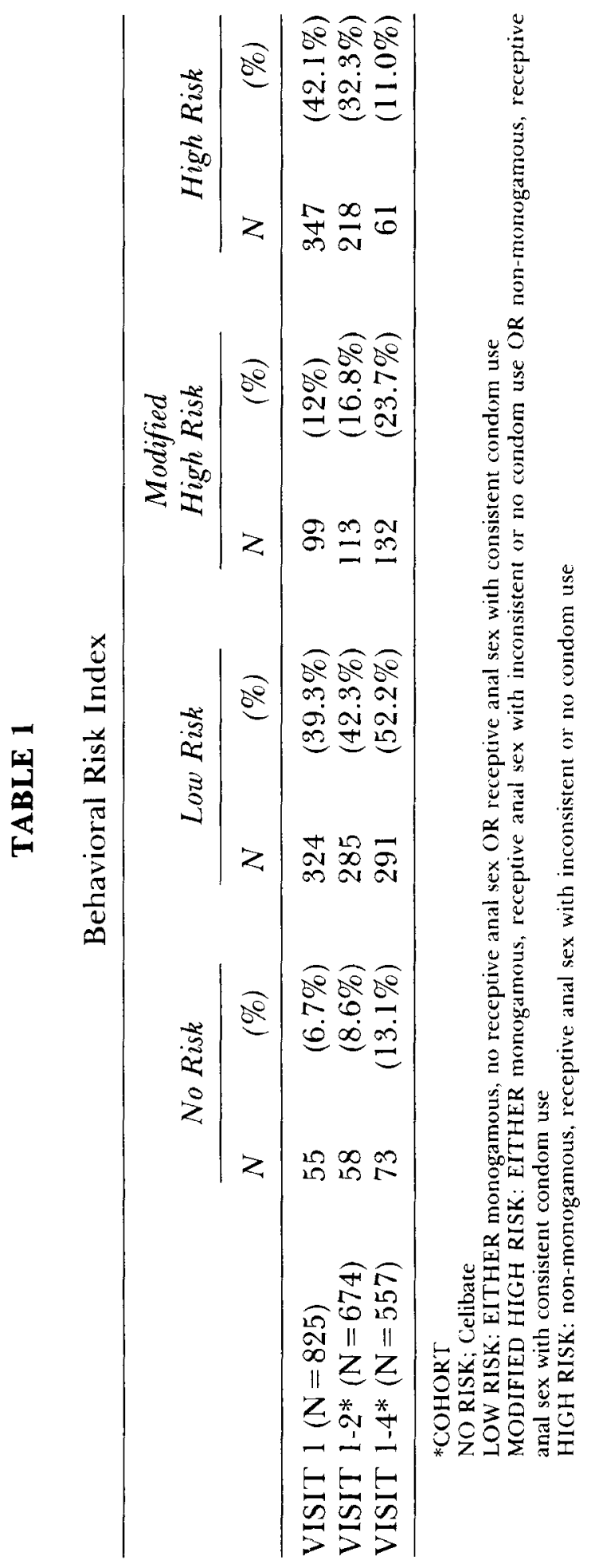




\section{FIGURE 1}

Hypothesis model: Gay identity variables predicting risky sexual behavior.

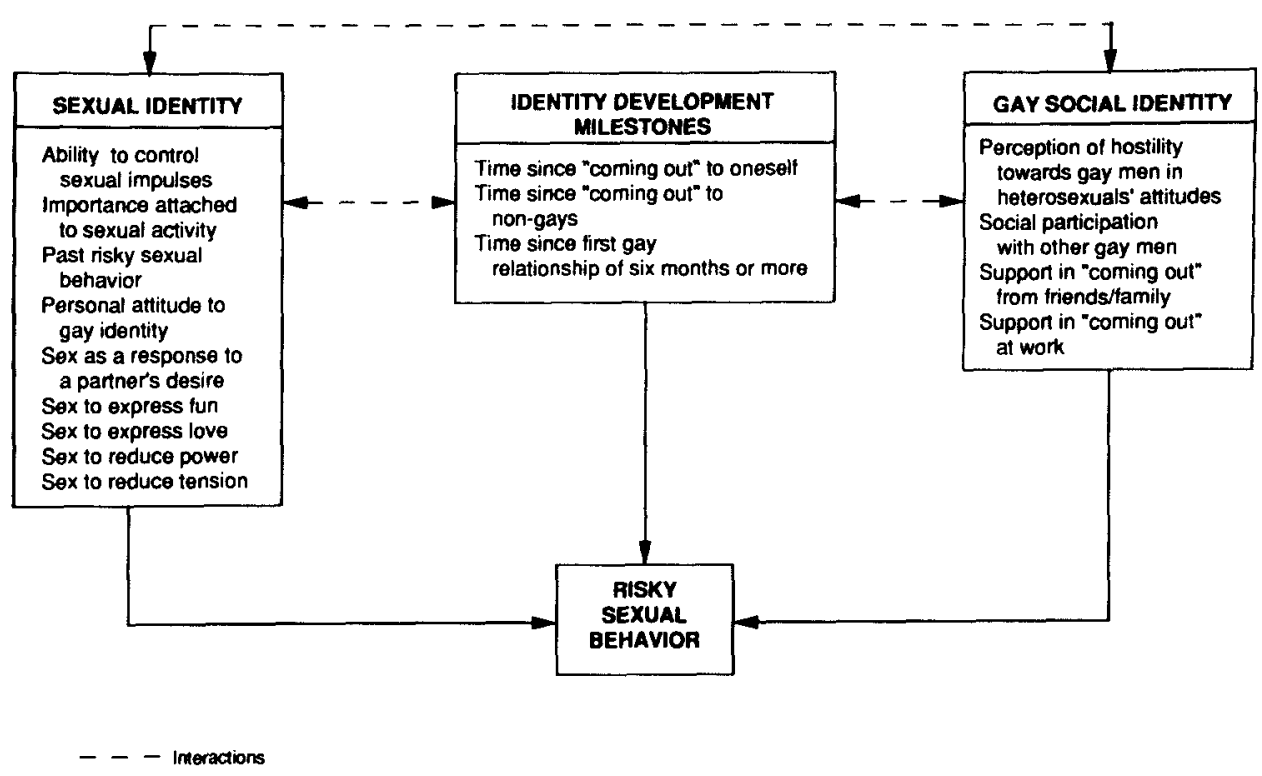

2. Is there a change on short or long-term intervals in these variables' predictive abilities?

\section{Statistical Procedures}

Longitudinal effect of independent variables from V1 on BRI at V2 and V4 was evaluated by means of a multiple linear regression analysis. "Trimmed" models were developed using a statistical significance inclusion cutoff at $p<0.10$. Interactions between variables with main effects were tested and included in the model when significant.

\section{RESULTS}

BRI measures are presented in Table 1 . BRI at V1 was used as a predictor of higher-risk in the V1-V2 cohort $(\mathrm{N}=657)$ and the V1-V4 cohort $(\mathrm{N}=557)$. Men dropping out between $\mathrm{V} 1$ and $\mathrm{V} 2(\mathrm{~N}=17)$, and between $\mathrm{Vl}$ and V4 $(\mathrm{N}=150)$ did not differ from participants on sociodemographic variables. However, dropouts at V4 were more likely to 


\section{TABLE 2}

Independent Variables Included In The Multivariate Regression As Predictors Of Subsequent Sexual Behavior

\begin{tabular}{|c|c|c|c|}
\hline Predictors & Range & Mean & $S D$ \\
\hline \multicolumn{4}{|l|}{ SEXUAL IDEN'TITY } \\
\hline Risk level at $\mathrm{V} 1^{*}$ & $1-4$ & 2.9 & 1.0 \\
\hline \multicolumn{4}{|l|}{ Needs met by sex $* * *$} \\
\hline sex to express love & $1-5$ & 3.8 & 1.2 \\
\hline sex to express power & $1-5$ & 2.1 & 1.2 \\
\hline sex to have fun & $1-5$ & 4.5 & 0.8 \\
\hline sex to reduce tension & $1-5$ & 3.6 & 1.1 \\
\hline $\begin{array}{l}\text { sex response to partner's } \\
\text { desire }\end{array}$ & $1-5$ & 2.8 & 1.3 \\
\hline $\begin{array}{l}\text { Importance attached to sexual } \\
\text { activity*** }\end{array}$ & $1-5$ & 4.2 & 0.9 \\
\hline Control on sexual impulses*** & $1-5$ & 3.3 & 1.6 \\
\hline $\begin{array}{l}\text { Personal attitude to gay } \\
\text { identity** }\end{array}$ & $1-100$ & 79.8 & 22.3 \\
\hline \multicolumn{4}{|l|}{ IDENTITY MILESTONES } \\
\hline $\begin{array}{l}\text { First considered yourself gay } \\
\quad \text { (years ago) }\end{array}$ & $0-70$ & 14.7 & 8.8 \\
\hline $\begin{array}{l}\text { First "came out" to non-gay } \\
\text { persons (years ago) }\end{array}$ & $0-68$ & 12.0 & 7.6 \\
\hline $\begin{array}{l}\text { Had first relationship that } \\
\text { lasted six months or more }\end{array}$ & $0-32$ & 5.5 & 3.2 \\
\hline \multicolumn{4}{|l|}{ GAY SOCIAL IDENTITY } \\
\hline $\begin{array}{l}\text { Social participation with other } \\
\text { gay men*** }\end{array}$ & $1-5$ & 2.6 & 0.9 \\
\hline $\begin{array}{l}\text { Perceived hostility in } \\
\text { heterosexuals' attitudes } \\
\text { towards gay men** }\end{array}$ & $1-100$ & 50.8 & 18.7 \\
\hline $\begin{array}{l}\text { Support in "coming out" from } \\
\text { significant others (family } \\
\text { and friends)** }\end{array}$ & $0-4$ & 2.1 & 1.1 \\
\hline $\begin{array}{l}\text { Support in "coming out" at } \\
\text { work** }\end{array}$ & $0-2$ & 1.1 & 0.9 \\
\hline
\end{tabular}

* See table for details of behavioral index.

**See appendix 1 for corresponding questions and indices construction.

****Range from 1 (not at all) to 5 (very much). 
belong to the two higher-risk behavioral categories than participants, though the odds-ratio fails to attain strict statistical significance (oddsratio $=1.56 ; 95 \%$ confidence interval: $0.97-2.15)$. The incidence of AIDS was significantly higher among drop-outs at V4 (16\%).

Table 2 shows average values for all predictors included in the analysis, whereas Table 3 presents the predictive "trim" models at V2 and V4.

Most variables and indices included in the "sexual identity category" predicted risk behavior in one or both models. Past risk behavior (at V1) showed the most significant effect among all predictors both at $\mathrm{V} 2$ and V4. This variable alone accounted for 17 percent of the total

\section{TABLE 3}

Multiple Linear Regression Models Predicting Sexual Behavior Risk

\begin{tabular}{|c|c|c|}
\hline \multirow[b]{2}{*}{ Predictors (V1) } & \multicolumn{2}{|c|}{ Regression Coefficient (beta) } \\
\hline & $\begin{array}{l}\text { Short-Term } \\
(\text { V2) } \\
(N=442)\end{array}$ & $\begin{array}{l}\text { Long-Term } \\
\quad(V 4) \\
(N=439)\end{array}$ \\
\hline Risk behavior at VI & $0.39 \mathrm{I}^{* * *}$ & $0.220^{* * *}$ \\
\hline Sex to express love & $0.076^{* *}$ & NS \\
\hline Sex to express power & $-0.080^{* *}$ & $-0.079 * *$ \\
\hline $\begin{array}{l}\text { Sex as a response to partner's } \\
\text { desire }\end{array}$ & $0.047^{*}$ & $0.047 *$ \\
\hline $\begin{array}{l}\text { Difficulty to control sexual } \\
\text { impulses }\end{array}$ & $0.051^{*}$ & $0.058 * * *$ \\
\hline $\begin{array}{l}\text { Personal attitude to gay } \\
\text { identity }\end{array}$ & $0.004^{*}$ & $0.003 * *$ \\
\hline $\begin{array}{l}\text { Importance attached to } \\
\text { sexual activity }\end{array}$ & $0.107 * *$ & $0.074^{*}$ \\
\hline $\begin{array}{l}\text { Social participation with other } \\
\text { gay men, among men with } \\
\text { higher positive attitude to } \\
\text { their own gay identity }\end{array}$ & $-0.307 * *$ & NS \\
\hline
\end{tabular}

$$
\begin{aligned}
& * p<.0 .10 \\
& * * p<0.05 \\
& * * * p<0.01
\end{aligned}
$$


variance in sexual risk at $\mathrm{V} 2$ and 8 percent of the total variance at V4. Other variables showing significant predictive effect in the trimmed models never accounted individually for more than 1-2 percent of the total variance.

Three of the five "needs met by sex" had a significant predictive effect on BRI. Men who were more likely to consider sex as an expression of love were also more likely to engage in higher-risk sexual behavior at V2 (but not at V4). Sex as an expression of power showed the opposite tendency, both at V2 and V4. In both models, the analysis suggests that the more a man engages in sex as a response to a partner's desire, the higher his risk behavior. Greater difficulty in controlling sexual impulses, higher importance attached to sexual activity, and more positive attitude to one's gay identity significantly predicted higher risk behavior in both models.

Men in this cohort started considering themselves gay ("being out" to themselves) on average 14.7 years ago (95\% of the cohort had been out between 12 and 18 years ago). Average age of "coming out" was 19.6 years of age. They first disclosed their sexual preference to a non-gay person at 23, and had their first relationship of six or more months on average 5.5 years after first considering oneself gay. None of these milestones was significantly associated with subsequent sexual behavior.

None of the gay social identity variables had a significant predictive effect on BRI. However, social participation with other gay men interacted with personal attitude to one's gay identity at V2, suggesting that higher participation with other gay men supports safer practices among men strongly committed to their gay identity.

\section{DISCUSSION}

The data analyzed in this paper were collected from a homogeneous group of mostly white, middle-class, well-educated, urban, selfidentified gay men in their mid-thirties. Findings derived from such a cohort can only be generalized to a similar group of gay men.

In the short-term model (at V2), higher risk behavior was associated with higher past risk (at V1), greater difficulty in controlling sexual activity, stronger positive attitude toward one's gay identity, and stronger tendencies to engage in sex as an expression of love. Lower risk behavior was associated with using sex as an expression of power, and actively socializing with other gay men. 
In the long-term model (at V4), higher risk behavior was associated with higher past risk behavior (at V1); greater personal importance placed on sex, stronger positive attitudes toward one's gay identity; and, strong tendencies to engage in sex as a response to a partner's desire. As in the short-term model, low risk behavior was associated with engaging in sex as an expression of power.

In this analysis, past sexual behavior was by far the strongest predictor of future sexual behavior. Many of the sexual identity variables, however, did show some ability to predict future sexual risk tendencies. Some of these variables, such as "sex for love" or "sex because of a partner's desire," can be understood as an "other" motivated sexual orientation. In essence, such an orientation is motivated by inter-relational considerations such as fulfilling a partner's sexual demands, or expressing love toward another. On the other hand, it seems those men who have better sexual impulse control and attach less importance to sexual activity in "being gay" were less likely to engage in risk behavior when they found a way of expressing their gay identity in social interaction with other gay men. It is interesting to note that in both the shortterm and long-term models a stronger positive attitude toward gay identity is associated with higher risk behavior, except when there was a higher degree of social participation with other gay men.

These findings tend to suggest that men who are securely incorporated in their network, who have mastered skills of negotiation and social interaction with their peers, and who place a lower importance on sexual activity as part of their gay identity, would find it easier to change risky sexual behavior. To take this a step further, homosexual men who experience their gay identity as more than simply a matter of sexual preference and sexual expression may find it easier, in the long run, to not only change their sexual behavior but participate in their "gayness" in such a way as to sustain such changes while satisfying their identity needs as gay men. In essence, these men draw from a wider array of experiences, attitudes, and means of expression to bolster their personal identities. One might speculate that in the earlier "explorative" stage of gay identity development, a gay man might have a narrower experience of what it means to be gay, and attach their identities as gay men more directly to how they view and express themselves sexually. If this were true, we might expect to find men in the earlier stages of their "coming out" process to be more likely to engage in higher risk sex.

Some empirical findings about gay identity formation suggest that greater social and sexual experimentation can be expected in gay men in the earlier "exploration" stages of gay identity development. 
Still, there is controversy as to whether historical milestones in the development of one's personal gay identity have an impact on gay sexual activity and social interaction. Our finding, as well as McKusick's ${ }^{5}$ lead to the conclusion that one's ability to reduce risky sexual behavior is tied at least as much to sexual habituation as to historical position in their process of gay identity development. In our analysis, the failure of developmental variable to predict directly risky sexual behavior can be due, in part, to the presence of other variables related to sexual habituation. It could also be due to the absence of variability in the range of time most men reported "coming out" (12 years on average, with 95 percent of the cohort reporting "being out" between nine and 17 years ago).

If sexual habituation is indeed related to personal history, it would indicate that future education and prevention efforts should be directed toward those individuals in the process of "coming out" who have not as yet found their place within the gay network. Such efforts should include strategies to improve social skills for these individuals, and to help them integrate themselves more fully into a positive implication, such a practice may improve motivation and support for safer sexual behavior. On the other hand, if this socialization process is associated more with psychological conditions rather than developmental evolution, such education strategies might not prove as effective. Indeed, both possibilities are not mutually exclusive. Further research beyond the scope of this paper, might elicit a subgroup of gay men for whom specific kinds of preventive strategies should be devised to help encourage their adherence to lower risk sexual behavior.

\section{REFERENCES}

1. Centers for Disease Control: HIV/AIDS surveillance report. January 1990: ]-22.

2. Stall RD, Coates TJ, Hoff C: Behavioral risk reduction for HIV infection among gay and bisexual men. A review of results from the United States. Am Psychol 1988, 43: 878-885.

3. Centers for Disease Control: Trends in gonorrhea in homosexually active men-King County, Washington, 1989. MMWR 1989; 38:762-764.

4. Becker $\mathrm{MH}$ and Joseph JG: AIDS and behavioral change to reduce risk: A review. Am J Public Health 1988; 78:394-410.

5. McKusick L, Horstman W, Coates TJ: AIDS and sexual behavior reported by gay men in San Francisco. Am J Public Health 1985; 75:493-496.

6. Cass YC: Homosexual identity: A concept in need of definition. J Homosex 1984; 9:105-126.

7. Weinberg TS: On 'doing' and 'being' gay: Sexual behavior and homosexual male self-identity. J Homosex 1978; 4:143-156.

8. Cass YC: Homosexual identity formation: A theoretical model. J Homosex 1979; 4:219-235.

9. Coleman E: Developmental stages of the coming out process. J Homosex 1982; 7:31-43.

10. McDonald GJ: Individual differences in the coming out process for gay men: Implications for the theoretical models. I Homosex 1982; 8:47-60.

11. Minton HL, McDonald GJ: Homosexual identity formation as a developmental process. J Homosex 1984; 9:91-104. 
12. Kingsley AL, Kaslow R, Rinaldo CR, et al.: Risk factors for seroconversion to human immunodeficiency virus among male homosexuals. Lancet 1987; 8529:345-348.

13. Emmons CA, Joseph JG, Kessler RC, Wortman CB, Montgomery SB, Ostrow DG: Psychosocial predictors of reported behavior change in homosexual men at risk for AIDS. Health Educ Q 1986; 13:331-345.

14. Joseph JG, Montgomery SB, Emmons CA, et al: Perceived risk of AIDS: Assessing the behavioral and psychological consequences in a cohort of gay men. Journal of Applied Social Psychology 1987; 17:216-230. 